\title{
Profiling of ACC synthase gene (ACS11) expression in Arabidopsis induced by abiotic stresses
}

\author{
Hee-Dong Eun ${ }^{\dagger}$, Sajid $\mathrm{Ali}^{\dagger}$, Hyeonjung Jung, Kihwan Kim and Won-Chan Kim ${ }^{*}$ (1)
}

\begin{abstract}
Abiotic stress induce the production of 1-aminocyclopropane-1-carboxylate (ACC), the precursor of ethylene by activating the enzyme ACC synthase. There are twelve ACC synthase genes reported in the genome of Arabidopsis, and the ACC synthase 11 (ACS11) gene encodes a polypeptide that is functional; however, its involvement in ethylene biosynthesis in response to abiotic stresses remains unclear. We evaluated the effects of higher ACC accumulation on A. thaliana seedlings in response to abiotic stressors such as flooding, salinity, cold, and drought. Transgenic plants were generated with ACS11 (ACS11-OX), and they demonstrated that overexpression of ACS11 reduces both root and shoot length observed in seedlings. RT-PCR analysis revealed that abiotic stressors induce the expression of the wild type ACS11 gene. Histochemical staining revealed that GUS activity followed the same time course as induction of wild type ACS11 gene expression, increased ACC levels, and production of stress hormone, ethylene. One finding showed that although induction of wild type ACS11 gene occurs under drought stress, GUS activity was highest at $6 \mathrm{~h}$ of drought stress and decreased to levels similar to control seedlings at 12 and $24 \mathrm{~h}$. Thus, Wild type ACS11 expression is involved in ACC production, and abiotic stressors induce the expression of ACS11 gene. Moreover, ACC increases in response to abiotic stress lead to the production of ethylene. All of the data presented here suggest that the overexpression of ACS11 paves the way for the production of stress hormone, ethylene, which adversely affected the growth and development of the plant.
\end{abstract}

Keywords: Abiotic stress, ACC synthase, ACS11, Arabidopsis, GUS assay, Ethylene

\section{Introduction}

Plants growth and development are adversely affected by unfavorable environmental conditions such as extreme temperature, salinity, drought, and flooding conditions. Salinity and drought are the major abiotic stressors that adversely affect more than $20 \%$ of arable and about $40 \%$ of irrigated land worldwide. In addition, approximately one-third of the world's irrigated land is considered to be affected by salinity and extreme temperature $[1,2]$. Abiotic stresses severely affect crop yields in general, but for grains, abiotic stresses decrease survival, biomass, and

\footnotetext{
*Correspondence: kwc@knu.ac.kr

${ }^{\dagger}$ Hee-Dong Eun and Sajid Ali equally contributed and are considered co-first authors

School of Applied Biosciences, Kyungpook National University, Daegu 41566, Republic of Korea
}

grain yield by more than $50 \%$ [2-4]. When plants are continuously exposed to stressful conditions in their natural environment, they not only demonstrate stress avoidance but also develop stress tolerance mechanisms $[5,6]$. In higher plants, increased levels of ethylene are produced in response to a number of different biotic and abiotic stressors. Typically, a very low concentration $(0.01 \mu \mathrm{l} / \mathrm{l})$ of ethylene is beneficial to the growth and development of plants; however, the 20-fold higher levels of ethylene typically produced under stressful conditions lead to physiological and anatomical damage [7-10].

Ethylene is a phytohormone that performs diverse regulatory functions in the growth and development of plants, including seed germination $[11,12]$ root growth $[13,14]$ fruit ripening $[15,16]$, and flower and leaf abscission $[17,18]$. Additionally, ethylene plays a key role in 
biotic and abiotic stress responses [19-21] and is considered an important modulator of plant growth and development. However, stress conditions elicit increased levels of ACC synthase, which in turn increases the amount of substrate ACC available to produce higher amount of ethylene in plant tissues. In other words, when plants are subjected to stressful conditions, they respond by producing stress hormone, ethylene. Glick et al. noted that the synthesis of stress hormone, ethylene occurs in two different peaks in which the magnitude of the first ethylene peak is much smaller than that of the second peak $[22,23]$. Additionally, ethylene has been shown to be a signaling molecule for different stress responses and for pathways that control plant growth and development. However, higher concentration of ethylene also has negative effects such as early flower abscission, senescence, and abnormal plant growth and development [23, 24]. The biosynthetic pathway of ethylene is well established in plants $[25,26]$. Typically, the amino acid methionine is converted into $S$-adenosyl-L-methionine (SAM) by the action of SAM synthetase. Then SAM is converted into ACC by ACC synthase; however, this reaction also forms 5-methylthioadenosine (MTA), which is recycled back into the amino acid methionine by a multistep pathway also known as the Yang cycle [27]. Meanwhile, ACC is converted into ethylene by ACC oxidase.

ACC synthase performs the rate-limiting step in ethylene biosynthesis [28]. In higher plants, the regulation of the rate of ethylene biosynthesis occurs at ACC formation; therefore, ACC synthase is a key regulator of both normal and ethylene production. ACC synthase is a cytosolic protein with a short half-life and requires pyridoxal phosphate as a cofactor for its activity. The published $\mathrm{X}$-ray structure of ACC synthase provides a basis for the rational design of inhibitors for agriculture applications [27-29]. Several studies report that ACC accumulation is stimulated by biotic and abiotic stress conditions. Under drought conditions, wheat leaves produce 30 -fold more ethylene within $4 \mathrm{~h}$, and these fluctuations in ethylene production occur in parallel with increases and decreases in substrate ACC levels [30]. Another study observed differential accumulation of $S$-adenosylmethionine synthetase (AdoMet) transcripts in response to salinity stress conditions, a relevant finding because AdoMet produces the substrate for ACC synthase in the ethylene biosynthetic pathway [31]. Similarly, a study that measured the effect of cold stress on ACC levels in coldtolerant and cold-sensitive maize inbreeds concluded that ACC accumulation was higher in the cold-sensitive maize (Co-125) inbreed compare to the cold-tolerant one [32]. Hence, a detailed study on the role of ACC synthase gene expression and ACC accumulation will contribute to our understanding of ethylene's role in plant growth and development. Additionally, such a study can pave the way toward understanding how plants respond to different environmental stresses and how to improve sustainable agriculture. In higher plant species, almost every genome carries multiple genes that encode for ACC synthase polypeptides [33,34]. Five ACC synthase genes are reported in rice plants [35] and Solanum tuberosum [36]. Eight ACC synthase genes were reported in tomato [37, 38]. Each ACC synthase gene in these multigene families are expressed throughout the plant life cycle and each is differentially regulated in response to environmental factors [33]. However, the Arabidopsis genome contains twelve ACC synthase genes (ACS1-ACS12) on five different chromosomes [34, 39]. Among the twelve $A C S$ genes, ACS2, ACS4, ACS5, ACS6, ACS7, ACS8, ACS9, and $A C S 11$ encode functional ACC synthases; however, $A C S 10$ and ACS12 encode aminotransferases and ACS3 is a pseudogene $[40,41]$.

When ACC synthase genes are upregulated, the amount of defensive proteins increases. Higher levels of ACC synthase pave the way for increased ACC production that in turn produces stress hormone, ethylene in response to the condition that triggered the upregulation. The presence of stress hormone, ethylene is detrimental to plant growth and development and is involved in initiating undesirable processes such as chlorosis, leaf abscission, and senescence. In the present study, we tested the hypothesis that plants under different abiotic stresses (flooding, drought, salinity, and cold) would upregulate ACS11 expression and accumulate increased levels of ACC in plant tissues, resulting in stress hormone, ethylene levels that could adversely affect the plant. Hence, the ACS11 gene and its promoter were used to study the role of the ACS11 gene product, a type-2 ACC synthase, and the role of ACC accumulation in the growth and development of the model plant (A. thaliana) under normal conditions and under conditions of abiotic stresses.

\section{Materials and methods \\ Plant growth conditions}

We evaluated Arabidopsis thaliana, ecotype Columbia (Col-0), in a growth chamber at $23{ }^{\circ} \mathrm{C}$ for $16 \mathrm{~h}$ of light, and at $21{ }^{\circ} \mathrm{C}$ for $8 \mathrm{~h}$ of dark, at $60 \%$ relative humidity, according to the growth conditions described by [42] For phenotypic analysis of ACS11 transgenic plants, wild type $A$. thaliana and the T2 generation of ACS11-OX plants were grown on soil under the same conditions. To confirm phenotypic changes in root lengths of wild type and ACS11-OX seedlings, all the seeds were surface sterilized with seed disinfectant (25\% bleach and $0.01 \%$ Triton $\mathrm{X}-100$ ) for $10 \mathrm{~min}$, then rinsed with distilled water three times. Surface sterilized seeds were germinated and grown on filter paper by plating on $0.5 \times$ Murashige and 
Skoog ( $1 / 2$ MS $)$ medium (0.8\% agar, $1 \%$ sucrose, $0.6 \mathrm{mM}$ MES [Sigma], pH 5.7) plates at $20{ }^{\circ} \mathrm{C}$ for 4 days. After 4 days, seedlings were transferred to the same plate for measurement of their root lengths. However, some seedlings were transferred to pots filled with soil and grown at $20{ }^{\circ} \mathrm{C}$ under controlled conditions for further experiments. The plants were analyzed with a minimum of three biological replicates per line in this research.

\section{Genomic DNA extraction and plasmid construction}

For extraction of genomic DNA, the rosette leaves were ground with a pestle in a $1.5 \mathrm{ml}$ micro-centrifuge tube, $500 \mu \mathrm{l}$ of buffer was added, and then vortexed to mix thoroughly. The tube was centrifuged for $5 \mathrm{~min}$ at $13,000 \times g$, the supernatant was transferred to a new tube, and an equivalent volume of isopropanol added to the transferred supernatant. The tube was inverted approximately 20 times to mix and then centrifuged for $10 \mathrm{~min}$ at $13,000 \times g$. After discarding the supernatant, $500 \mu \mathrm{l}$ of $70 \%$ ethanol was added to wash the precipitate. The tube was centrifuged for $2 \mathrm{~min}$ at 13,000, the supernatant was discarded, and the pellet was dried for 10-15 min. The DNA pellet was resuspended in $20 \mu \mathrm{l}$ of DNase-free water. Plasmids were constructed by PCR amplification with specific primers. The $1383 \mathrm{bp}$ coding sequence of the A. thaliana ACS11 (AtACS11) gene was amplified from cDNA and the AtACS11 promoter, including the 1076 bp immediately upstream of the $5^{\prime}$-untranslated region of the AtACS11 mRNA was amplified from genomic DNA (Additional file 1: Table S1). PCR conditions for cDNA were as follows: $94{ }^{\circ} \mathrm{C}$ for 5 min; followed by 35 cycles of $94{ }^{\circ} \mathrm{C}$ for $20 \mathrm{~s}, 59{ }^{\circ} \mathrm{C}$ for $40 \mathrm{~s}$, and $72{ }^{\circ} \mathrm{C}$ for $1 \mathrm{~min} 10 \mathrm{~s}$; then $72{ }^{\circ} \mathrm{C}$ for $5 \mathrm{~min}$. PCR conditions for genomic DNA were as follows: $94{ }^{\circ} \mathrm{C}$ for $5 \mathrm{~min}$; followed by 35 cycles of $94{ }^{\circ} \mathrm{C}$ for $20 \mathrm{~s}, 55^{\circ} \mathrm{C}$ for $40 \mathrm{~s}$, and $72{ }^{\circ} \mathrm{C}$ for $1 \mathrm{~min}$; then $72{ }^{\circ} \mathrm{C}$ for $5 \mathrm{~min}$. The AtACS11 coding sequence fragment was inserted into the pCB302-3 binary vector, and the AtACS11 promoter fragment was inserted into the pCB308 binary vector using ligase (Promega). More information about the AtACS11 gene and promoter regions can be found at TAIR (http://www. arabidopsis.org/).

\section{RNA isolation and CDNA synthesis}

For total RNA isolation, rosette leaf and cotyledon of Arabidopsis were ground in a $1.5 \mathrm{ml}$ micro-centrifuge tube to a fine powder with a pestle under liquid nitrogen $\left(\mathrm{LN}_{2}\right)$. The detailed method of [43] was adopted with some modifications. By using TRI$\mathrm{zol}^{\mathrm{TM}}$ reagents the total RNAs were extracted from the crushed leaves of Arabidopsis (Thermo Scientific; USA). Total RNA concentration was determined by $\mathrm{A}_{260} / \mathrm{A}_{280}$ ratio using a spectrophotometer (Eppendorf,
Bio-Spectrophotometer ${ }^{\circledR}$ ). For cDNA synthesis a total of $1 \mu \mathrm{g}$ of total RNA was used by using SuperScript ${ }^{\circledR}$ III (Invitrogen; USA). The cDNA $(1 \mu \mathrm{l})$ was used for quantitative real time PCR using Taq polymerase (New England BioLabs; Ipswich, MA, USA) with 30 cycles of amplification using selected primers. For sequencing of ACS11 gene and ACS11 promoter in the constructed vectors, a $30 \mu \mathrm{l}$ of E. coli (DH5 $\alpha$ ) was inoculated in $3 \mathrm{ml}$ of LuriaBertani (LB) broth for the preparation of competent cells.

\section{Cloning of $A C S 11$ gene and $A C S 11$ promoter}

After construction, each vector was transformed into $E$. coli competent cells. A $5 \mu$ sample of ligated vectors (10$15 \mathrm{ng} / \mu \mathrm{l}$ ) was added to $50 \mu \mathrm{l}$ of $E$. coli competent cells and incubated on ice for $30 \mathrm{~min}$. Competent cells with ligated vectors were heated at $42{ }^{\circ} \mathrm{C}$ for $45 \mathrm{~s}$ and then incubated on ice for $2 \mathrm{~min}$. After that, the samples were incubated at $37^{\circ} \mathrm{C}$ for $50 \mathrm{~min}$ in $100 \mu \mathrm{l}$ of SOC media. Transformed cells were inoculated into LB agar plates containing kanamycin antibiotic. Plates were incubated at $37^{\circ} \mathrm{C}$ for $15 \mathrm{~h}$, and colony PCR was performed to confirm the transformation. Confirmed colonies were isolated and incubated at $37{ }^{\circ} \mathrm{C}$ in LB broth, and plasmid DNA was prepared using EZ-Pure ${ }^{\mathrm{TM}}$ Plasmid Prep kit Ver.2 (Enzynomics). $A C S 11$ gene and $A C S 11$ promoter sequence inserted into vectors were sent to SOLGENT (Korea) for sequencing.

\section{Arabidopsis transformation}

The detail method of [44] was adopted for the transformation of Arabidopsis with some modifications. Prior to Arabidopsis transformation the construction of vectors with target sequences was also confirmed in $A$. tumefaciens (GV3101) competent cells on LB agar plates containing kanamycin and rifampicin antibiotics. The independent transformants were screened on $1 / 2 \mathrm{MS}$ media. The seedlings were grown for 10 days at $23{ }^{\circ} \mathrm{C}$ for $16 \mathrm{~h}$ of light and $21{ }^{\circ} \mathrm{C}$ for $8 \mathrm{~h}$ of dark in $60 \%$ relative humidity. Finally, the seedlings were used for the evaluation of GUS histochemical staining under different conditions such as drought, salinity, cold and flooding.

\section{Abiotic stress treatments}

Salinity stress was evaluated on $1 / 2$ MS agar plates with $100 \mathrm{mM} \mathrm{NaCl}$. Plate composition and growth conditions were the same as mentioned above. At 4 days after sowing, wild type and transgenic seedlings were transferred to $1 / 2$ MS agar plates containing $\mathrm{NaCl}$ $(100 \mathrm{mM})$ and grown for 10 days. Seedlings were evaluated and survival rates were assessed until the end of the experiment. For flooding, drought, and cold stress, wild type and ACS11-OX transgenic plants were either plated on $1 / 2$ MS agar plates or grown in the same pots for 3 weeks in soil. Flooding stress was evaluated by 
using plastic buckets for treated plants, cold stress was evaluated at $4{ }^{\circ} \mathrm{C}$ for $12 \mathrm{~h}$, and drought stress was evaluated on $1 / 2$ MS agar plates containing 0.25 MPa PEG.

\section{GUS histochemical staining}

ACS11 promoter transgenic plants were grown 4 days after sowing on $1 / 2$ MS agar plates and then transferred onto different $1 / 2$ MS agar plates. Seedlings were grown vertically for 10 days and retransferred onto two different plates for abiotic stress assessment. For the evaluation of salinity stress, the seedlings were transferred to $1 / 2$ MS agar plates with a high salt concentration $(200 \mathrm{mM} \mathrm{NaCl})$. For flooding stress, the seedlings were submerged in water. For cold stress, the plants were placed at $4{ }^{\circ} \mathrm{C}$ in a refrigerator. For drought stress, the seedlings were subjected to $0.25 \mathrm{MPa}$ PEG in $1 / 2 \mathrm{MS}$ agar plates. After abiotic stress treatments for $3,6,12$, and $24 \mathrm{~h}$, seedlings were vacuum infiltrated in GUS staining buffer for $3-5 \mathrm{~min}$ and stained at $37{ }^{\circ} \mathrm{C}$ for $12 \mathrm{~h}$. Stained seedlings were assessed for chlorophyll with $70 \%(v / v)$ ethanol.

\section{Statistical analysis}

The experiments were repeated in triplicates, whereas the data collected from each treatment were compiled for further analysis. All the parameters were analyzed in triplicate and the results were expressed as the mean \pm SD. Error bars represent standard deviation (SD). Asterisks were used to denote the values that were significantly different $(\mathrm{P}<0.01)$ by $t$ test.

\section{Results}

\section{Phenotypic analysis of ACS11-OX transgenic seedlings}

The A. thaliana genome contains twelve ACC synthase genes (ACS1-ACS12). In this study, we focused our analysis on the role of $A C S 11$ expression, ACC accumulation, and stress hormone, ethylene production in response to different abiotic stress conditions. To investigate how ACS11 participates in ethylene biosynthesis and plant phenotype, we constructed transgenic $A$. thaliana plants that overexpress ACS11 cDNA under the control of the Cauliflower Mosaic Virus (CMV) $35 \mathrm{~S}$ promoter. The sequence alignment of $A C S$ with its close isozymes in Arabidopsis were also revealed (Fig. 1). Where the gray shading box correspond to similar amino acid residues

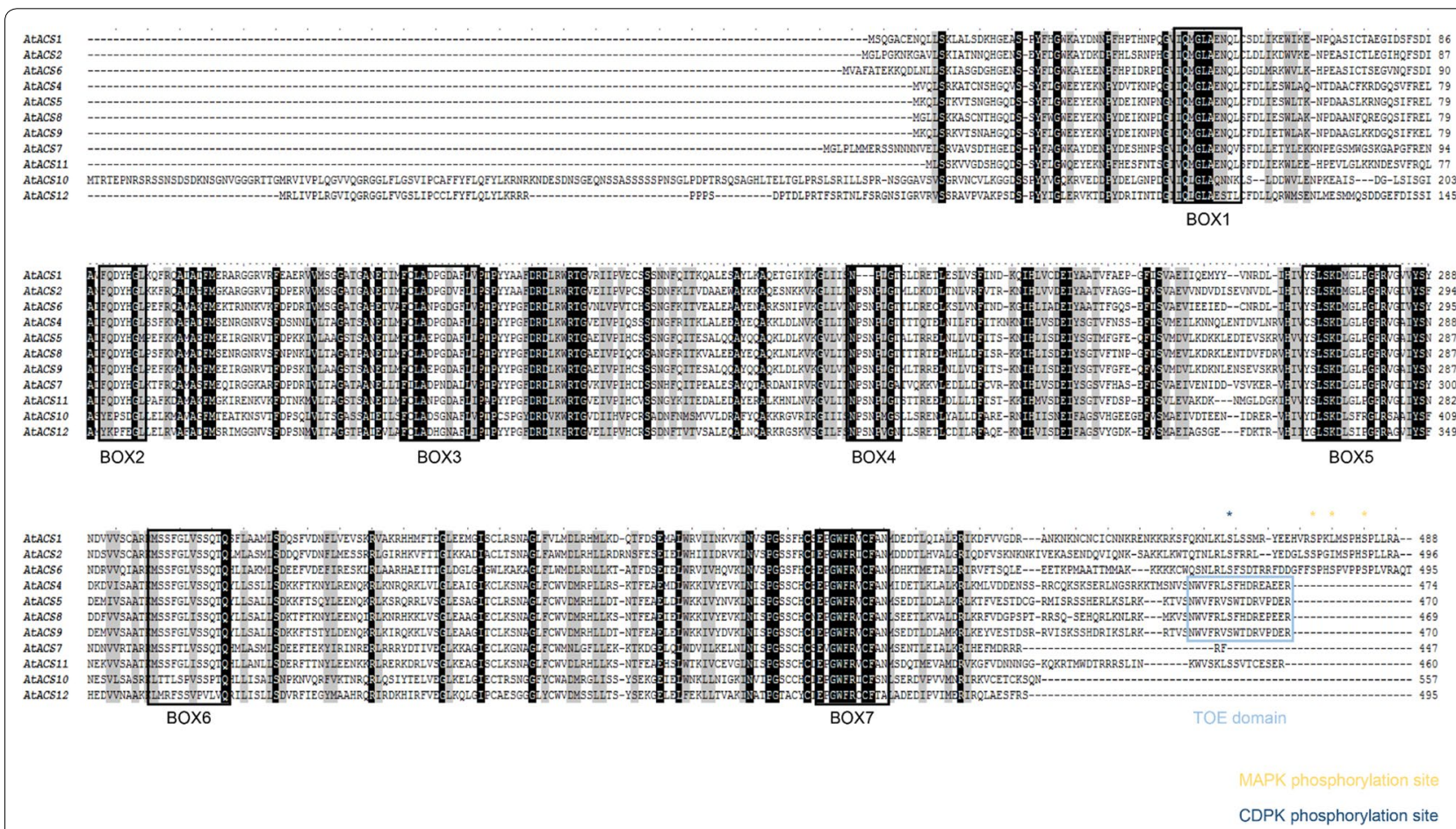

Fig. 1 Sequence alignment of ACS with its close isozymes in Arabidopsis thaliana. Alignment of the amino acid sequence from AtACS1 (NP_191710), AtACS2 (NP_171655), AtACS4 (NP_179866). AtACS5 (NP_201381), AtACS6 (NP_192867), AtACS7 (NP_194350), AtACS8 (NP_195491), AtACS9

(NP_190539), AtACS10 (NP_564804), AtACS11 (NP_567330), AtACS12 (NP_199982) using ClustalW. The black shading box correspond to identical amino acid residues. The gray shading box correspond to similar amino acid residues. The seven conserved domains of the ACS isozymes are marked as boxes 1-7. The serine (S) residue marked with a blue and yellow asterisk is implicated in calcium-dependent protein kinase (CDPK) and mitogen-activated protein kinase (MAPK) phosphorylation site, respectively 
and the conserved domains of the ACS isozymes were marked as boxes 1-7. By using Agrobacterium-mediated transformation via the floral dip method, T2 transgenic lines of Arabidopsis (Col-0) were assigned as ACS11-OX (strong) or ACS11-OX (weak) lines according to RT-PCR band intensity of ACS11 compared to wild type (Fig. 2).

Overexpression of ACS11 affected the root length of transgenic ACS11-OX (strong) seedlings compared to wild type seedlings at 10 days growth; whereas, the root phenotype of ACS11-OX (weak) seedlings was similar to wild type seedlings (Fig. 2a). Similarly, the roots of wild type and transgenic Arabidopsis revealed a significant difference ( $\mathrm{P}<0.01$ by $\mathrm{t}$-test) in their lengths: $5.31 \pm 0.51 \mathrm{~cm}$ in wild type and $3.28 \pm 0.38 \mathrm{~cm}$ in ACS11-OX (strong) seedlings (Fig. 2b). Therefore, it is likely that overexpression of ACS11 in ACS11-OX (strong) lines increases ACC, the immediate precursor of stress hormone, ethylene, which adversely affects seedling growth and inhibits normal root elongation (Fig. 2c). Furthermore, we compared the rate of root growth by measuring root length on daily basis for 6 days and observed that the ACS11OX (strong) seedlings had a notably lower root growth rate compared to wild type and ACS11-OX (weak) seedlings (Fig. 2d).

For further phenotypic analysis, wild type and ACS11OX transgenic seeds were grown in soil for extended times and plant phenotype was evaluated each week. We observed a hyponastic response in 4-week-old transgenic plants. ACS11-OX plants also had smaller leaves and shorter petioles than wild type plants at 4 weeks, and the shoot length of transgenic plants was also shorter than wild type and similar to a dwarf phenotype after 5 weeks
(Fig. 3a). Comparing the shoot length of wild type and ACS11-OX in 6-week-old seedlings, wild type plants measured $28.86 \pm 1.36 \mathrm{~cm}$ tall, and ACS11-OX measured $22.83 \pm 1.95 \mathrm{~cm}$ tall, a significant difference $(\mathrm{P}<0.01)$ (Fig. 3b). The phenotype of wild type and ACS11-OX plants grown in soil with limited hours of daylight revealed similar results. Hence, overexpression of ACS11 in Arabidopsis inhibits normal growth and development in these transgenic plants (Fig. 3c). The results presented here suggest that the overexpression of ACS11 paves the way for the production of stress hormone, ethylene which affect the normal developmental processes of the plant.

\section{ACS11-OX transgenic plants and abiotic stresses tolerance}

Abiotic stressors are known for their prominent role in the regulation of ACC synthase gene expression. Here, we compared the effects of ACC synthase 11 (ACS11) gene expression in wild type and transgenic $A$. thaliana plants that overexpress ACS11 (ACS11-OX) under different abiotic stress conditions. Salinity stress tolerance was analyzed on $1 / 2$ MS agar plates (Fig. 4). Four-dayold wild type and ACS11-OX transgenic seedlings were transferred to the $1 / 2 \mathrm{MS}$ agar plates with $100 \mathrm{mM} \mathrm{NaCl}$, and survival was recorded after 6 days (Fig. 4a). Survival rates between wild type and the ACS11-OX (weak) line were $90 \pm 3.33 \%$ and $76.67 \pm 3.33 \%$, respectively, a significant difference $(\mathrm{P}<0.05)$ (Fig. 4b). Similarly, survival rates between wild type and the ACS11-OX (weak) line on the same plate also revealed survival rates: $93 \%$ and $63.33 \pm 3.33 \%$, respectively (Fig. 4c).

Another finding was that the leaves of ACS11-OX seedlings exhibited more rapid senescence under flooding
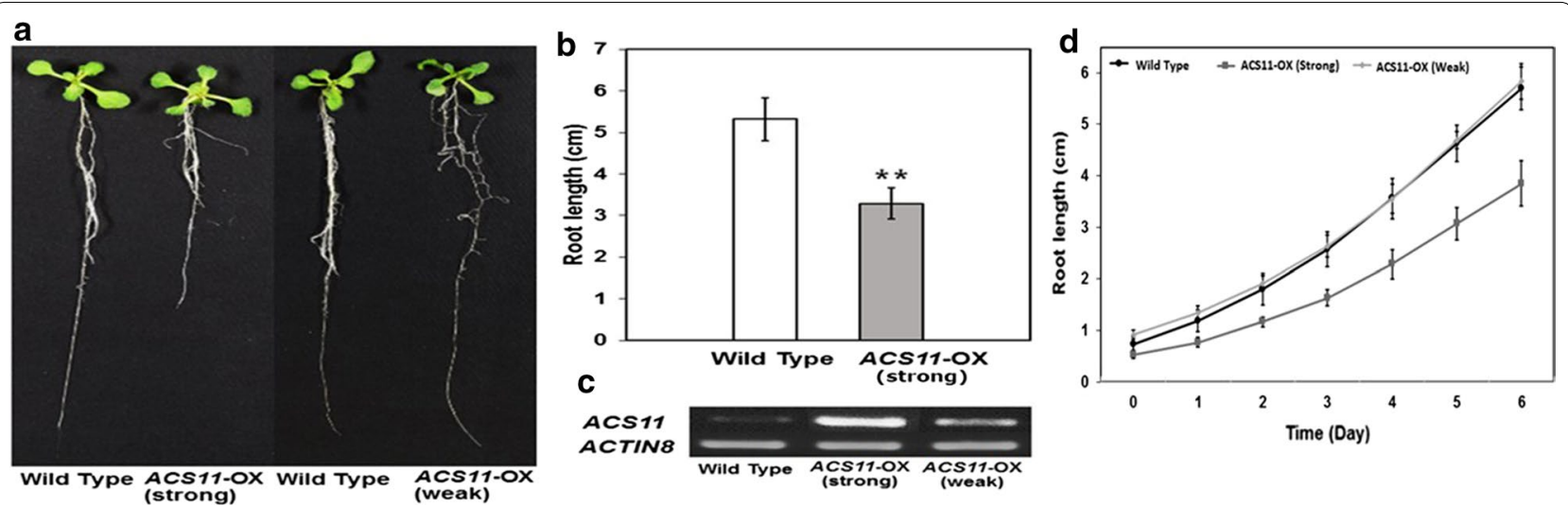

Fig. 2 Root phenotypic analysis of wild type and ACS11-OX transgenic seedlings on 1/2 MS agar plates. Seeds were grown for 4 days after sowing on $1 / 2$ MS agar plates, then transferred to different $1 / 2$ MS agar plates and grown for 6 days vertically. a Root phenotypes of wild type and ACS11-OX transgenic seedlings (strong, weak). b Root length of wild type and ACS11-OX (strong) seedlings. Error bars represent standard deviation (SD). Values denoted by ${ }^{* *}$ were significantly different $(P<0.01)$ by t-test. $\mathbf{c}$ RT-PCR analysis of ACS11 expression in wild type and ACS11-OX transgenic seedlings. ACTIN8 was used as a control. d Time-course analysis of root growth rate. Four-day-old seedlings were transferred to different $1 / 2 \mathrm{MS}$ agar plates, and root lengths were measured daily for 6 days. A lower root growth rate was noted in ACS11-OX (strong) seedlings relative to wild type seedlings; however, ACS11-OX (weak) seedling root growth rate was similar to that of wild type seedlings 
a

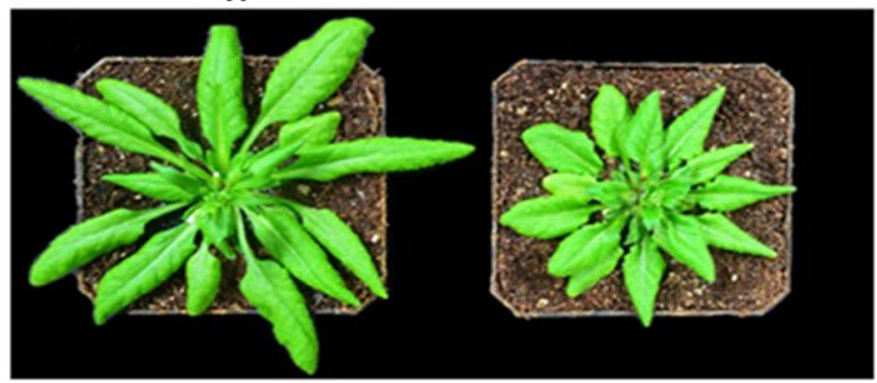

C

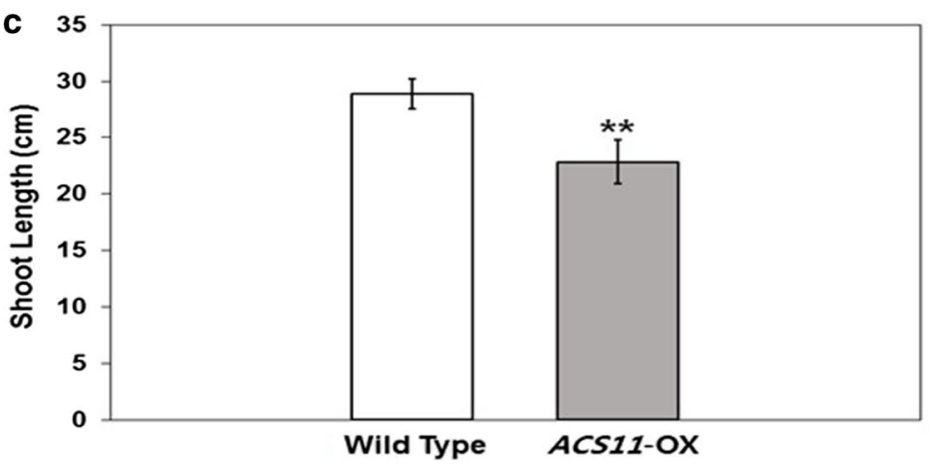

b

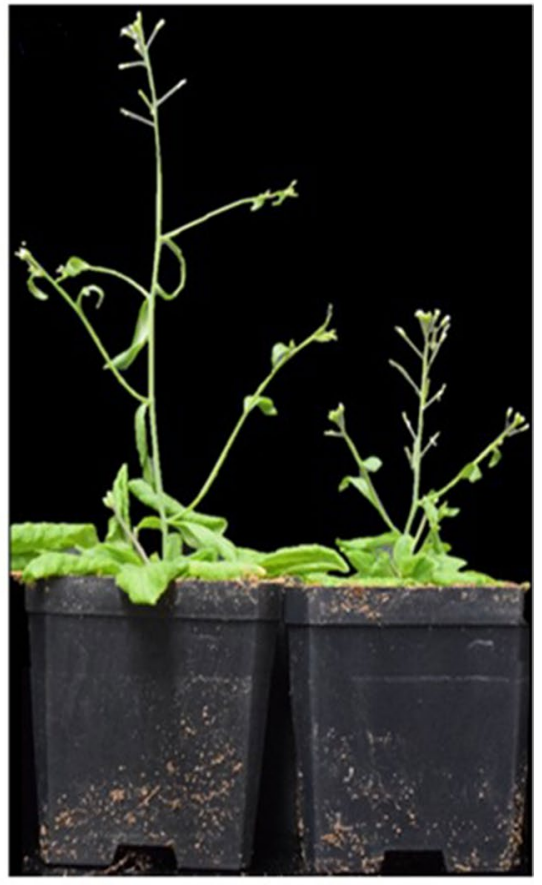

Fig. 3 Phenotypic analysis of wild type (plant on the left in each image) and ACS11-OX transgenic Arabidopsis (plant on the right in each image) seeds cultivated in soil. a, b Representative of 4-, and 5-week-old plants, respectively. c Measurement of shoot lengths in 6-week-old plants revealed that ACS11-OX shoots were significantly shorter compared to wild type plants. Error bars represent standard deviation (SD). Values denoted by ** were significantly different $(P<0.01)$ by t-test

compared to wild type seedlings. Flooding and cold stress tolerance were also analyzed by growth in soil. To induce flooding stress, 21-day-old plants were submerged in water using plastic buckets kept at $23{ }^{\circ} \mathrm{C}$ for $16 \mathrm{~h}$ of light and $21^{\circ} \mathrm{C}$ for $8 \mathrm{~h}$ of dark. Changes were noted on a daily basis for both wild type and ACS11-OX submerged seedlings. At 3 days, ACS11-OX plants exhibited more leaf senescence than wild type plants, and at 5 days, ACS11-OX plants showed higher levels of coloring agents (anthocyanin) than wild type plants (Fig. 5).

In a similar experiment, 21-day-old plants were subjected to cold stress by alternating between $23{ }^{\circ} \mathrm{C}$ for $12 \mathrm{~h}$ with light and $4{ }^{\circ} \mathrm{C}$ for $12 \mathrm{~h}$ in the dark. There was no observable difference between wild type and ACS11OX plant through 6 days of cold stress. However, ACS11OX transgenic plants did show symptoms after more than 6 days of cold stress (Fig. 6). These soil growth experiments comparing wild type and ACS11-OX transgenic plants under normal and various stress conditions showed that the overexpression of ACC synthase cDNA in ACS11-OX plants produced increased levels of ACC, which was then readily available for conversion to stress hormone, ethylene. Thus, ACS11-OX transgenic plants were more vulnerable to salinity, flooding, and cold stress than wild type plants.

\section{Effect of abiotic stress on the expression of ACS11 gene}

To evaluate the expression of the wild type ACS11 gene in response to abiotic stresses, we assayed for the presence of $A C S 11$ mRNA by RT-PCR at different time points $(0,0.5,1,2,6$, and $12 \mathrm{~h})$ after subjecting wild type seedlings to abiotic stressors (Fig. 7). The observed expression levels of ACS11 under abiotic stresses revealed that, except when plants were subjected to drought stress, ACS11 mRNA was induced at different time points. The sequence of the wild type ACS11 promoter is shown in Fig. 8.

To confirm these results in vivo as well as in vitro, the proACS11::GUS region of the pCB308 vector was introduced into wild type $A$. thaliana by using Agrobacterium-mediated plant transformation. The $\mathrm{T} 1$ generation of transgenic seeds was germinated on $1 / 2$ MS agar plates and grown for 4 days and then transferred to different $1 / 2$ MS agar plates. After 10 days, transgenic seedlings were transferred to appropriate $1 / 2$ MS agar plates for abiotic stress treatments. Plants exposed to each treatment were 

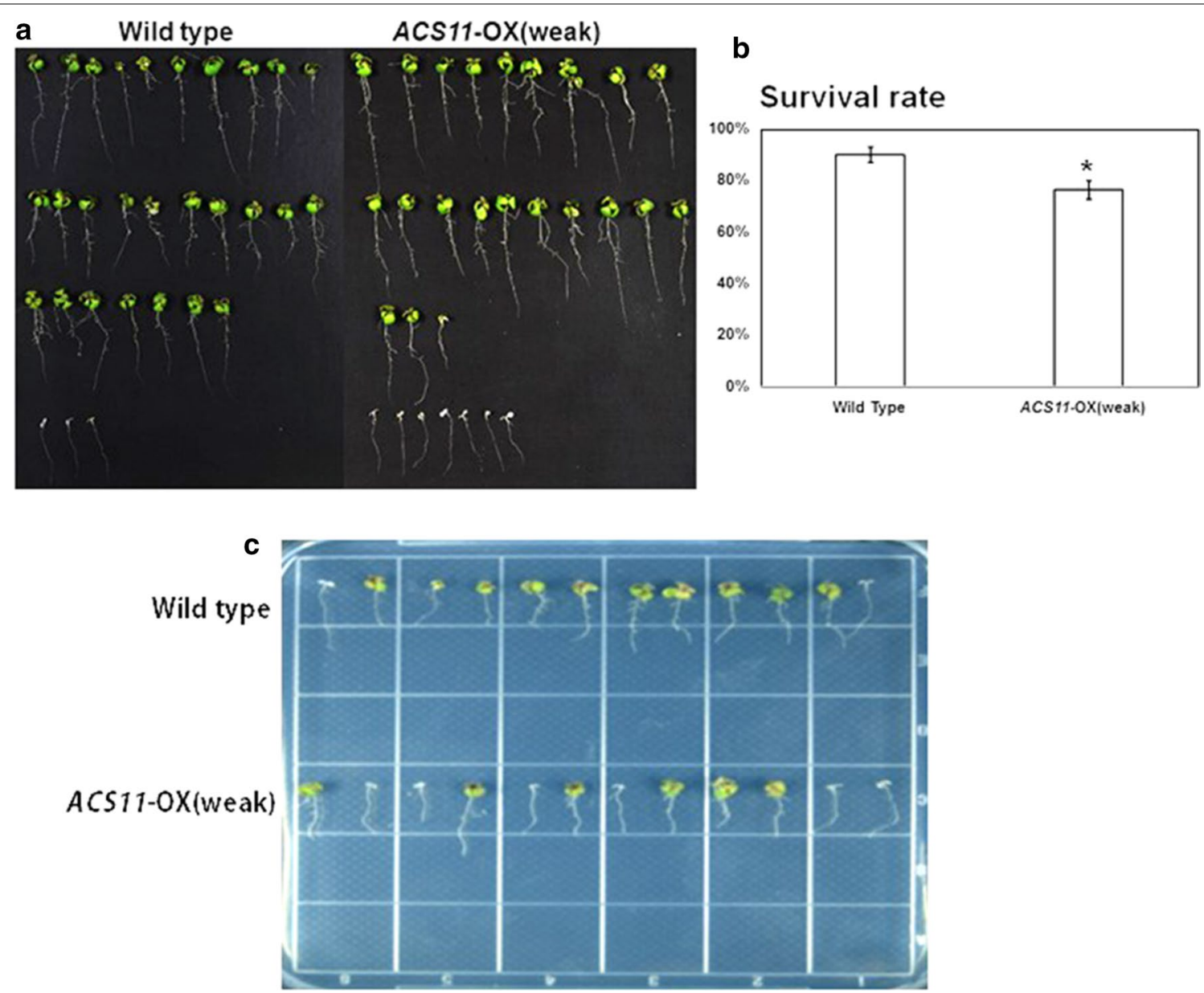

Fig. 4 Survival rates of wild type and ACS11-OX (weak) line on 1/2 MS medium under salinity stress. a Survival rates of 10-day-old wild type and ACS11-OX (weak) line on $1 / 2 \mathrm{MS}$ medium under salinity stress (100 mM NaCl). b Percentage of survival rate of wild type and ACS11-OX (weak) line on $1 / 2$ MS medium under salinity stress. Error bars represent standard deviation (SD). Values denoted by an * were significantly different $(P<0.05)$ by t-test. c A wild type and ACS11-OX (weak) grown on the same plate, 1/2 MS medium under salinity stress (100 mM NaCl)

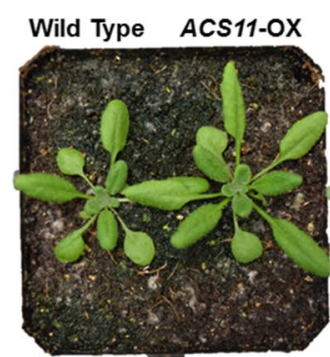

1 day

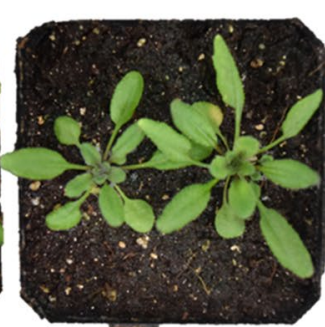

3 day

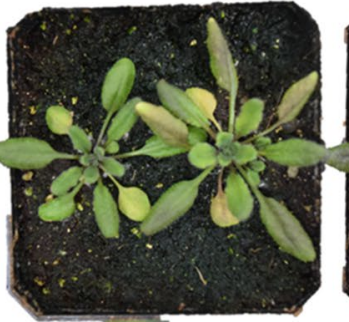

4 day

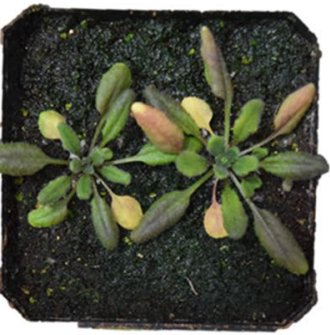

5 day

Fig. 5 Phenotypic analysis of 21-day-old wild type (plant on the left in each image) and ACS11-OX (plant on the right in each image) seedlings that were subjected to flooding stress for the indicated periods of time 


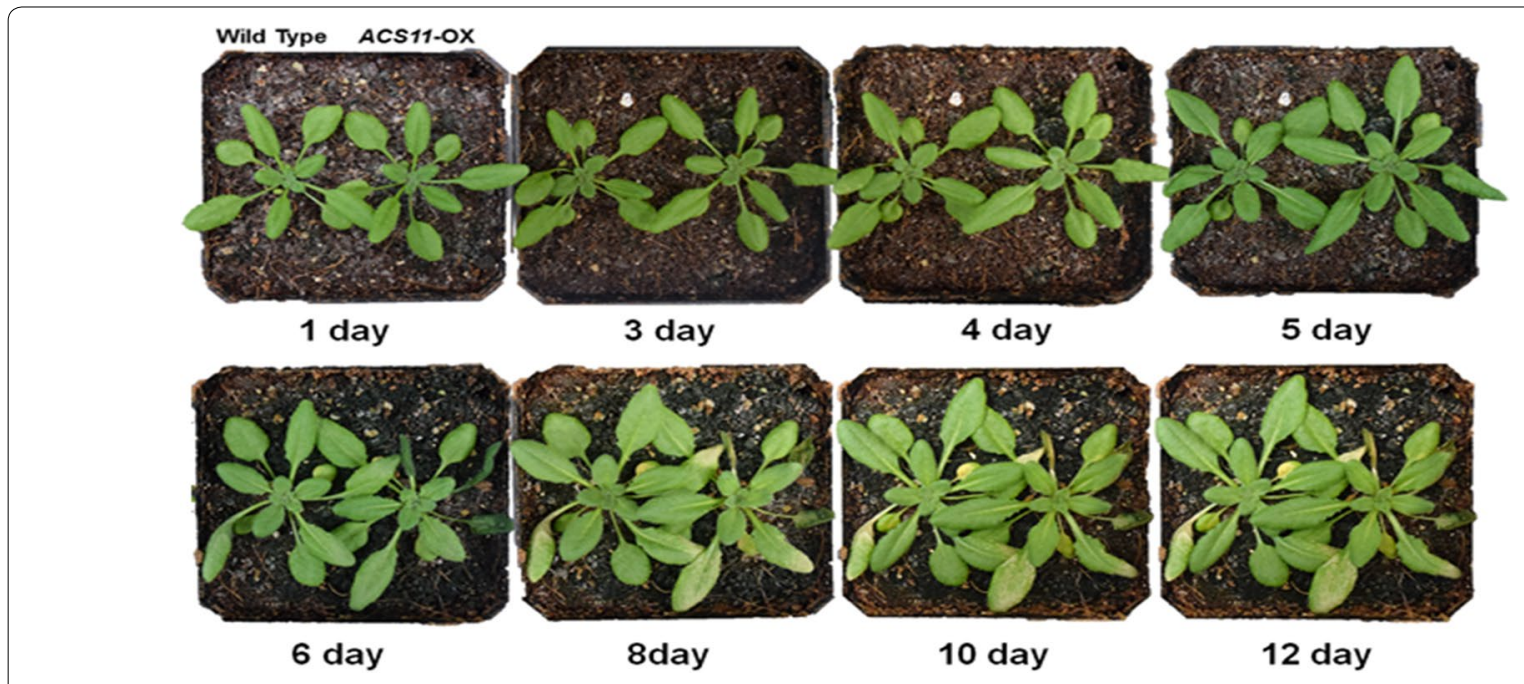

Fig. 6 Phenotypic analysis of 21-day-old wild type (plant on the left in each image) and ACS11-OX (plant on the right in each image) seedlings that were subjected to cold stress for the indicated periods of time

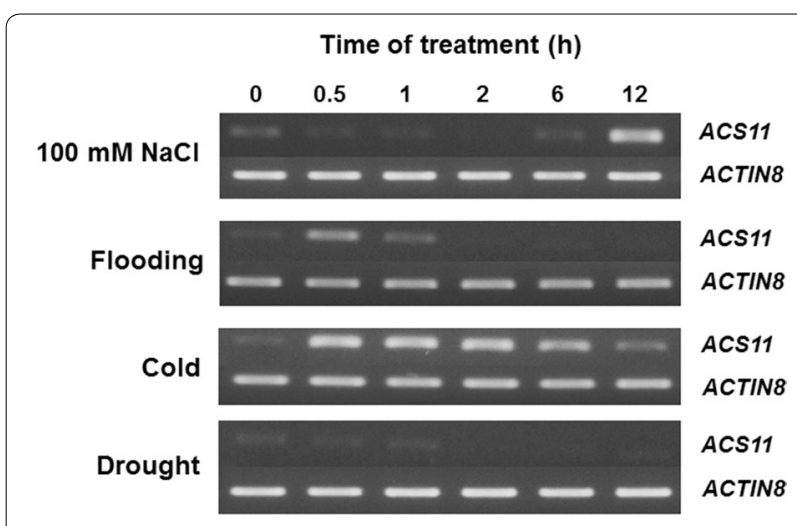

Fig. 7 Time-course of ACS11 mRNA expression by RT-PCR analysis under abiotic stress. Wild type seedlings were subjected to abiotic stresses such as salinity (100 mM NaCl), flooding, cold, and drought for the indicated times. ACTIN8 was used as a control. The number of PCR amplification cycles were as follows: ACTIN8, 27 cycles; ACS11, 29 cycles

subjected to histochemical staining at $0,3,6,12$, and $24 \mathrm{~h}$.

Flooding stress was evaluated by submerging plants in pots filled with water. GUS activity in response to flooding stress was observable after $3 \mathrm{~h}$ and was highest at $24 \mathrm{~h}$ of flooding stress (Additional file 2: Fig. S1A). Similarly, seedlings were subjected to salinity stress (200 mM $\mathrm{NaCl}$ ) in $1 / 2 \mathrm{MS}$ agar plates. GUS activity was elevated at 6,12 , and $24 \mathrm{~h}$ of salinity stress (Additional file 2: Fig. S1B). Similarly the effect of drought stress was evaluated using 0.25 MPa PEG-infused plates. GUS activity was highest at $6 \mathrm{~h}$ of drought stress and decreased to levels similar to those of control seedlings at 12 and $24 \mathrm{~h}$ (Additional file 2: Fig. S1C). Finally, cold stress was evaluated by transferring seedlings to $4{ }^{\circ} \mathrm{C}$ in the dark. GUS activity was highest at $6 \mathrm{~h}$ of cold stress, decreased at $12 \mathrm{~h}$, and then interestingly increased again at $24 \mathrm{~h}$ (Additional file 2: Fig. S1D). These results indicate that ACS11 is induced by salinity, flooding, drought, and cold stress in vivo.

\section{Discussion}

Various abiotic stresses are deleterious to plant growth and development and negatively affect crop productivity and yield $[45,46]$. However, plants have evolved robust, adaptive mechanisms to survive in adverse environmental conditions [47]. Many plants increase expression of one or more genes that encode ACC synthase, which in turn produce $\mathrm{ACC}$ in response to stressful environments [26]. ACC is the immediate precursor of ethylene, and fluctuations in ethylene biosynthesis affect plant growth and development. This study focused on ACS11 expression and regulation during plant growth and development as well as in response to different abiotic stresses. Additionally, in vitro and in vivo experiments were performed to evaluate the effect of fluctuations in ACS11 expression on the activity of ACC synthase in response to abiotic stresses (Additional file 2: Fig. S1).

Phylogenetic analysis of the ACS gene family has already shown that there are different $A C S$ genes in Arabidopsis [40]. Expression of ACS4, ACS5, and ACS7 genes has been shown to be induced by hormones and environmental stresses [34]. For this study, transgenic Arabidopsis plants that overexpress the ACS11 gene, 


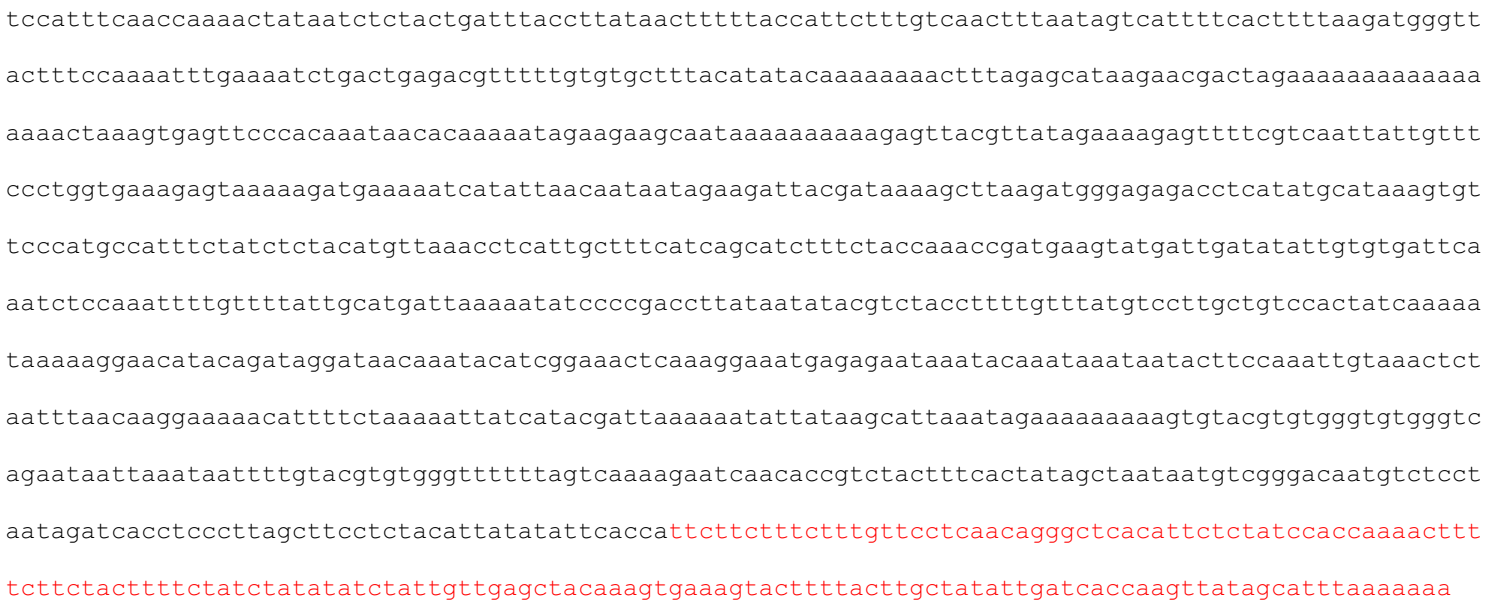

Fig. 8 The nucleotide sequence of the wild type ACS11 promoter; $1076 \mathrm{bp}$

which encodes a type-2 ACC synthase, were constructed and used for phenotypic analysis by comparison with wild type plants under normal growth conditions (Figs. 2, 3, 4) and under conditions of specific abiotic stresses (Figs. 5, 6). More interestingly, the results from phenotypic variation in wild type and transgenic plants validated our hypothesis that upregulation of $A C S 11$ expression could adversely affect the plant because the leaves, roots, and shoots of transgenic plants were shorter than that of wild type (Figs. 2, 3, 4). Additionally, tolerance to salinity, flooding, and cold stresses was reduced in the transgenic ACS11-OX seedlings compared to wild type seedlings. Other studies have found that plants respond to stressful conditions by synthesizing increased amounts of the enzyme ACC synthase as well as other stress proteins. Under flooding stress, the upregulation of ACC synthase leads to an accumulation of ACC in the roots, and because ACC requires molecular oxygen to be converted into ethylene, the ACC is transported to the shoots where it has access to oxygen [23, 48, 49].

To evaluate endogenous ACS11 expression patterns under conditions of abiotic stress, wild type plants were subjected to abiotic stresses and the time course of ACS11 expression was measured by RT-PCR (Fig. 7). ACS11 expression was upregulated in response to the abiotic stresses of salinity, flooding, and cold, but not drought. Previous studies showed that GUS activity in the roots of Arabidopsis seedlings was apparent in the hypocotyl root junction and at a lower level in the vascular tissues of the roots after 4 days [50]. Another study fused the GUS reporter gene with the promoters of Arabidopsis ACS genes $A C S 4, A C S 5$, and $A C S 7$ to make ACS::GUS transgenic plants [34]. However, in this study, we used the histochemical GUS staining experiments to investigate
ACS11 promoter activity in vivo. ACS11 was upregulated when plants were subjected to abiotic stresses in a time course that was similar to the RT-PCR results. These findings are consistent with previously reported data; however, they provide no direct evidence on whether ACC and ethylene levels were elevated in transgenic plants by the upregulation of ACS11 specifically. Production of stress hormone, ethylene in plants causes physiological damage such as leaf chlorosis, wilting, necrosis, and reduced biomass [51]. However, it is possible to protect plants from the effects of stress hormone, ethylene by employing different strategies such as the inhibition of ACC synthase mRNA accumulation (through salicylic acid); the use of polyamines (spermidine, putrescine), which has also revealed anti-senescence properties; and the application of ACC-deaminase-producing bacteria under different stress conditions [23, 52, 53]. A recent report [54] showed the effect of abiotic stress on ACS8 and ethylene production. The study also reported the importance of ACS8 in defense response and early ethylene biosynthesis induced by copper ions in Arabidopsis plants. Moreover, to investigate the role of ACS2 and ACS6 in ethylene production they also evaluated the effects of $\mathrm{Cu}^{2+}$ on ACS2 and ACS6 double knockout mutant plants. Whereas, no significant difference was observed in the ethylene of wild type, ACS2 and ACS6 mutant plants at early stage $(2 \mathrm{~h})$, however, after $24 \mathrm{~h}$ ACS 2 and ACS6 induce the production of stress hormone, ethylene. Likewise, the study of Schellingen et al. [55] reported that abiotic stressors induce the production of stress hormone, ethylene in Arabidopsis by inducing the transcription of $A C S 6$ and ACS2. In connection to this, our results also suggest that ACS11-OX line affect the normal growth and development of the seedlings 
because of $A C S 11$ induction compare to wild type. Thus, the higher amount of stress hormone, ethylene produced by ACS11-OX line compare to wild type seedlings under abiotic stress conditions greatly affected the viability of the plants and arrest its normal growth and development.

\section{Additional files}

Additional file 1: Table S1. List of primers used in this experiments,

Additional file 2: Fig. S1. Analysis of ACS11 promoter activity in proACS11::GUS-expressing transgenic seedlings in response to different abiotic stressors for the specific periods of time. (A) Analysis of ACS11 promoter activity in proACS11::GUS-expressing transgenic seedlings in response to flooding stress for the indicated periods of time. (B) Analysis of ACS11 promoter activity in proACS11::GUS-expressing transgenic seedlings in response to salinity stress $(200 \mathrm{mM} \mathrm{NaCl})$ for the indicated periods of time. (C) Analysis of ACS11 promoter activity in proACS1 1::GUSexpressing transgenic seedlings in response to drought stress for the indicated periods of time. (D) Analysis of ACS11 promoter activity in proACS11:: GUS-expressing transgenic seedlings in response to cold stress for the indicated periods of time.

\section{Acknowledgements}

This work was carried out with the support of "Cooperative Research Program for Agriculture Science \& Technology Development (Project No. PJ01365701)" Rural Development Administration, Republic of Korea.

\section{Authors' contributions}

$\mathrm{HDE}, \mathrm{SA}, \mathrm{HJ}$, and KK performed the experiments, data analysis and manuscript writing; HDE, SA and WCK designed the experiment plan and revised the manuscript together. All authors read and approved the final manuscript.

\section{Competing interests}

The authors declare that they have no competing interests.

Received: 17 May 2019 Accepted: 1 August 2019

Published online: 08 August 2019

\section{References}

1. Xiong L, Schumaker KS, Zhu JK (2002) Cell signaling during cold, drought, and salt stress. Plant Cell. https://doi.org/10.1105/tpc.000596

2. Singhal P, Jan AT, Azam M, Haq QMR (2016) Plant abiotic stress: a prospective strategy of exploiting promoters as alternative to overcome the escalating burden. Front in Life Sci. https://doi.org/10.1080/21553 769.2015.1077478

3. Grover A, Kapoor A, Lakshmi OS, Agarwal S, Sahi C, Katiyar-Agarwal S, Dubey H (2001) Understanding molecular alphabets of the plant abiotic stress responses. Curr Sci. 80:206-216

4. Vij S, Tyagi AK (2007) Emerging trends in the functional genomics of the abiotic stress response in crop plants. Plant Biotechnol J. https://doi.org/1 0.1111/j.1467-7652.2007.00239.x

5. Anjum SA, Xie XY, Wang LC, Saleem MF, Man C, Lei W (2011) Morphological, physiological and biochemical responses of plants to drought stress. Afr J Agric Res. https://doi.org/10.5897/AJAR10.027

6. Duque AS, de Almeida AM, da Silva, AB, da Silva JM, Farinha AP, Santos D, de Sousa Araújo S (2013) Abiotic stress responses in plants: unraveling the complexity of genes and networks to survive. In: Abiotic stress-plant responses and applications in agriculture. Janeza Trdine 9, 51000 Rijeka, Croatia, pp 49-102

7. Reid MS (1995) Ethylene in plant growth, development, and senescence. Plant Hormo. https://doi.org/10.1007/978-94-011-0473-923
8. Ali S, Khan MA, Kim WC (2018) Pseudomonas veronii KJ mitigates flood stress-associated damage in Sesamum indicum L. Appl Biol Chem. https:// doi.org/10.1007/s13765-018-0392-2

9. Ullah I, Waqas M, Khan MA, Lee IJ, Kim WC (2017) Exogenous ascorbic acid mitigates flood stress damages of Vigna angularis. Appl Biol Chem. https://doi.org/10.1007/s13765-017-0316-6

10. Sasidharan R, Hartman S, Liu Z, Martopawiro S, Sajeev N, van Veen H, Voesenek LA (2018) Signal dynamics and interactions during flooding stress. Plant Physiol. https://doi.org/10.1104/pp.17.01232

11. Linkies A, Leubner-Metzger G (2012) Beyond gibberellins and abscisic acid: how ethylene and jasmonates control seed germination. Plant Cell Rep. https://doi.org/10.1007/s00299-011-1180-1

12. Kucera B, Cohn MA, Leubner-Metzger G (2005) Plant hormone interactions during seed dormancy release and germination. S Sci Res. https:// doi.org/10.1079/SSR2005218

13. Růžička K, Ljung K, Vanneste S, Podhorská R, Beeckman T, Friml J, Benková $E$ (2007) Ethylene regulates root growth through effects on auxin biosynthesis and transport-dependent auxin distribution. Plant Cell. https://doi. org/10.1105/tpc.107.052126

14. Sharp RE, LeNoble ME (2002) ABA, ethylene and the control of shoot and root growth under water stress. J Exp Bot. https://doi.org/10.1093/jexbo $\mathrm{t} / 53.366 .33$

15. Burg SP, Burg EA (1962) Role of ethylene in fruit ripening. Plant Physiol. 37(2):179-189

16. Zhang $M$, Yuan B, Leng P (2009) The role of ABA in triggering ethylene biosynthesis and ripening of tomato fruit. J Exp Bot. https://doi. org/10.1093/jxb/erp026

17. Aneja M, Gianfagna T, Ng E (1999) The roles of abscisic acid and ethylene in the abscission and senescence of cocoa flowers. Plant Grow Reg. https ://doi.org/10.1023/A:1006153502897

18. Iqbal N, Khan NA, Ferrante A, Trivellini A, Francini A, Khan MIR (2017) Ethylene role in plant growth, development and senescence: interaction with other phytohormones. Front Plant Sci. https://doi.org/10.3389/ fpls.2017.00475

19. Zhang M, Smith JAC, Harberd NP, Jiang C (2016) The regulatory roles of ethylene and reactive oxygen species (ROS) in plant salt stress responses. Plant Mol Biol. https://doi.org/10.1007/s11103-016-0488-1

20. Thao NP, Khan MIR, Thu NBA, Hoang XLT, Asgher M, Khan NA, Tran LSP (2015) Role of ethylene and its cross talk with other signaling molecules in plant responses to heavy metal stress. Plant Physiol. https://doi. org/10.1104/pp.15.00663

21. Abiri R, Shaharuddin NA, Maziah M, Yusof ZNB, Atabaki N, Sahebi M, Hanafi MM (2017) Role of ethylene and the APETALA 2/ethylene response factor superfamily in rice under various abiotic and biotic stress conditions. Environ Exp Bot. https://doi.org/10.1016/j.envexpbot.2016.10.015

22. Glick BR, Cheng Z, Czarny J, Duan J (2007) Promotion of plant growth by ACC deaminase-producing soil bacteria. New perspectives and approaches in plant growth-promoting Rhizobacteria research. Springer, Berlin. https://doi.org/10.1007/s10658-007-9162-4

23. Glick BR (2014) Bacteria with ACC deaminase can promote plant growth and help to feed the world. Microbiol Res. https://doi.org/10.1016/j.micre s.2013.09.009

24. Kacperska A, Kubacka-Zębalska M (1989) Formation of stress ethylene depends both on ACC synthesis and on the activity of free radical-generating system. Physiol Plantarum. https://doi. org/10.1111/j.1399-3054.1989.tb04974.x

25. Sauter M, Moffatt B, Saechao MC, Hell R, Wirtz M (2013) Methionine salvage and S-adenosylmethionine: essential links between sulfur, ethylene and polyamine biosynthesis. Biochem J. https://doi.org/10.1042/BJ201 21744

26. Ali S, Kim WC (2018) Plant growth promotion under water: decrease of waterlogging-induced ACC and ethylene levels by ACC deaminaseproducing bacteria. Front Microbiol. https://doi.org/10.3389/fmicb .2018 .01096

27. Yang SF, Hoffman NE (1984) Ethylene biosynthesis and its regulation in higher plants. Annu Rev Plant Physiol. https://doi.org/10.1146/annur ev.pp.35.060184.001103

28. Sato T, Theologis A (1989) Cloning the mRNA encoding 1-aminocyclopropane-1-carboxylate synthase, the key enzyme for ethylene biosynthesis in plants. Proc Natl Acad Sci. https://doi.org/10.1073/pnas.86.17.6621 
29. Capitani G, Hohenester E, Feng L, Storici P, Kirsch JF, Jansonius JN (1999) Structure of 1-aminocyclopropane-1-carboxylate synthase, a key enzyme in the biosynthesis of the plant hormone ethylene. J Mol Biol. https://doi. org/10.1006/jmbi.1999.3255

30. Apelbaum A, Yang SF (1981) Biosynthesis of stress ethylene induced by water deficit. Plant Physiol. https://doi.org/10.1104/pp.68.3.594

31. Espartero J, Pintor-Toro JA, Pardo JM (1994) Differential accumulation of S-adenosylmethionine synthetase transcripts in response to salt stress. Plant Mol Biol. https://doi.org/10.1007/BF00023239

32. Janowiak F, Dürffling K (1995) Chilling-induced changes in the contents of 1-aminocyclopropane-1-carboxylic acid (ACC) and its N-malonyl conjugate (MACC) in seedlings of two maize inbreds differing in chilling tolerance. J Plant Physiol. https://doi.org/10.1016/S0176-1617(11)81514-2

33. Wang KLC, Li H, Ecker JR (2002) Ethylene biosynthesis and signaling networks. Plant Cell. https://doi.org/10.1105/tpc.001768

34. Wang NN, Shih MC, Li N (2005) The GUS reporter-aided analysis of the promoter activities of Arabidopsis ACC synthase genes AtACS4, AtACS5, and AtACS7 induced by hormones and stresses. J Exp Bot. https://doi. org/10.1093/jxb/eri083

35. Van Der Straeten D, Zhou Z, Prinsen E, Van Onckelen HA, Van Montagu MC (2001) A comparative molecular-physiological study of submergence response in lowland and deepwater rice. Plant Physiol. https://doi. org/10.1104/pp.125.2.955

36. Destéfano-Beltrán LJ, Van Caeneghem W, Gielen J, Richard L, Van Montagu M, Van Der Straeten D (1995) Characterization of three members of the ACC synthase gene family in S tuberosum L. Mol Gen Genet. https:// doi.org/10.1007/BF00290453

37. Barry CS, Llop-Tous MI, Grierson D (2000) The regulation of 1-aminocyclopropane-1-carboxylic acid synthase gene expression during the transition from system-1 to 2 ethylene synthesis in tomato. Plant Physiol. https://doi.org/10.1104/pp.123.3.979

38. Rottmann WH, Peter GF, Oeller PW, Keller JA, Shen NF, Nagy BP, Theologis A (1991) 1-Aminocyclopropane-1-carboxylate synthase in tomato is encoded by a multigene family whose transcription is induced during fruit and floral senescence. J Mol Biol. https://doi.org/10.1016/00222836(91)90587-V

39. Arabidopsis Genome Initiative (2000) Analysis of the genome sequence of the flowering plant Arabidopsis thaliana. Nature. 408(6814):796

40. Yamagami T, Tsuchisaka A, Yamada K, Haddon WF, Harden LA, Theologis A (2003) Biochemical diversity among the 1-amino-cyclopropane-1-carboxylate synthase isozymes encoded by the Arabidopsis gene family. J Biol Chem. https://doi.org/10.1074/jbc.M308297200

41. Tsuchisaka A, Yu G, Jin H, Alonso JM, Ecker JR, Zhang X, Theologis A (2009) A combinatorial interplay among the 1-aminocyclopropane-1-carboxylate isoforms regulates ethylene biosynthesis in Arabidopsis thaliana. Genetics. https://doi.org/10.1534/genetics.109.107102

42. Lu B, Pei LK, Chan WK, Zhang H, Zhu G, Li J, Li N (2001) The dual effects of ethylene on the negative gravicurvature of Arabidopsis inflorescence, an intriguing action model for the plant hormone ethylene. Chin Sci Bull. https://doi.org/10.1007/BF03187185
43. Chan CX, Teo SS, Ho CL, Othman RY, Phang SM (2004) Optimisation of RNA extraction from Gracilaria changii (Gracilariales, Rhodophyta). J Appl Phycol. https://doi.org/10.1023/B:JAPH.0000047782.20940.de

44. Tague BW (2001) Germ-line transformation of Arabidopsis lasiocarpa. Trans Res. https://doi.org/10.1023/A:1016633617908

45. Alcazar R, Marco F, Cuevas JC, Patron M, Ferrando A, Carrasco P, Altabella $T$ (2006) Involvement of polyamines in plant response to abiotic stress. Biotechnol Lett. https://doi.org/10.1007/s10529-006-9179-3

46. Choudhury S, Panda P, Sahoo L, Panda SK (2013) Reactive oxygen species signaling in plants under abiotic stress. Plant Sign Behav. https://doi. org/10.4161/psb.23681

47. Bielach A, Hrtyan M, Tognetti VB (2017) Plants under stress: involvement of auxin and cytokinin. Int J Mol Sci. https://doi.org/10.3390/ijms180714 27

48. Li J, Sun J, Yang Y, Guo S, Glick BR (2012) Identification of hypoxic-responsive proteins in cucumber roots using a proteomic approach. Plant Physiol Biochem. https://doi.org/10.1016/j.plaphy.2011.10.011

49. Bradford KJ, Yang SF (1980) Xylem transport of 1-aminocyclopropane1-carboxylic acid, an ethylene precursor, in waterlogged tomato plants. Plant Physiol. https://doi.org/10.1104/pp.65.2.322

50. Rodrigues-Pousada RA, De Rycke R, Dedonder A, Van Caeneghem W, Engler G, Van Montagu M, Van Der Straeten D (1993) The Arabidopsis 1-aminocyclopropane-1-carboxylate synthase gene 1 is expressed during early development. Plant Cell. https://doi.org/10.1105/tpc.5.8.897

51. Barnawal D, Bharti N, Maji D, Chanotiya CS, Kalra A (2012) 1-Aminocyclopropane-1-carboxylic acid (ACC) deaminase-containing rhizobacteria protect Ocimum sanctum plants during waterlogging stress via reduced ethylene generation. Plant Physiol Biochem. https://doi.org/10.1016/j. plaphy.2012.07.008

52. Li N, Parsons BL, Liu D, Mattoo AK (1992) Accumulation of wound-inducible ACC synthase transcript in tomato fruit is inhibited by salicylic acid and polyamines. Plant Mol Biol. https://doi.org/10.1007/BF00040664

53. Ibal JC, Jung BK, Park CE, Shin JH (2018) Plant growth-promoting rhizobacteria used in South Korea. Appl Biol Chem. https://doi.org/10.1007/ s13765-018-0406-0

54. Zhang B, Liu H, Ding X, Qiu J, Zhang M, Chu Z (2018) Arabidopsis thaliana ACS8 plays a crucial role in the early biosynthesis of ethylene elicited by Cu2+ ions. J Cell Sci. https://doi.org/10.1242/jcs.202424

55. Schellingen K, Van Der Straeten D, Vandenbussche F, Prinsen E, Remans T, Vangronsveld J, Cuypers A (2014) Cadmium-induced ethylene production and responses in Arabidopsis thaliana rely on ACS2 and ACS6 gene expression. BMC Plant Biol. https://doi.org/10.1186/s12870-014-0214-6

\section{Publisher's Note}

Springer Nature remains neutral with regard to jurisdictional claims in published maps and institutional affiliations.

\section{Submit your manuscript to a SpringerOpen ${ }^{\circ}$ journal and benefit from:}

- Convenient online submission

- Rigorous peer review

- Open access: articles freely available online

- High visibility within the field

- Retaining the copyright to your article

Submit your next manuscript at springeropen.com 